\title{
The Effect of Convenience Store Dessert on Consumers Value and Satisfaction
}

\author{
Seong-Soo CHA*, Su-Han LEE** \\ Received: January 15, 2019 Revised: November 29, 2019 Accepted: February 06, 2020.
}

\begin{abstract}
This study aims to investigate what selection attributes of customer value are more crucial when consumers choose the dessert at convenience store, which is the fastest growing retail format in Korea recently. Factors considered to be important when customers buy dessert, such as economics, diversity, convenience, and safety were examined and also relationship between customer value and satisfaction was analyzed. The survey was conducted through online (including SNS) from April 6, 2019 to April 30, 2019. A total of 303 questionnaires were used for empirical analysis. Factor analysis was performed to verify the validity and reliability of the measured variables. And the structural equation model (SEM) was used as a statistical method for hypothesis testing. As a result, factors as 'diversity', 'safety' were revealed to significantly affect hedonic customer value, while 'convenience' was shown to affect utilitarian customer value significantly. In addition, the path that customer value leads to satisfaction was also found to be significant. The result of the study suggests that selection attributes of convenience store dessert and providing meaningful implications of related hedonic and utilitarian values when customers purchase dessert at convenience store. This study provided practical implications for managers of the fiercely competitive dessert industry.
\end{abstract}

Keywords : Convenience Store, Dessert, Hedonic Value, Utilitarian Value, Diversity

JEL Classification Code : D11, D12, L66, L81

\section{Introduction}

Recently, due to the development of the food culture and consumer lifestyle changes, eating-out trend is rapidly changing (Cha, Park, \& Wang, 2019). Large retailers, such as department stores, performed poorly due to sluggish consumer spending, while the domestic convenience store market has been growing at an average annual rate of $17 \%$ for the past five years in Korea (Kim, 2016). In 2013, the convenience store market growth was only $1.2 \%$, but grew rapidly to $4.7 \%$ in 2014 and $11.4 \%$ in 2016 , and sales amounted from 12 trillion won in 2013 to 14 trillion won in 2014 and 17 trillion won in 2016. It would increase to 20 trillion won, and is expected to grow by $19.3 \%$ in 2017 ,

*First Author, Assistant Professor, Dept. of Food Science \& Service, College of Bio-Convergence, Eulji University Tel: +82-31-740-7274, Email: sscha@eulji.ac.kr.

${ }^{* *}$ Corresponding Author, Professor, Dept. of Food Science \& Service, College of Bio-Convergence, Eulji University

Tel: +82-31-740-7196, Email: shlee@eulji.ac.kr

(c) Copyright: The Author(s)

This is an Open Access article distributed under the terms of the Creative Commons Attribution NonCommercial License (https://creativecommons.org/licenses/by-nc/4.0/) which permits unrestricted no commercial use, distribution, and reproduction in any medium, provided the original work is properly cited. exceeding 20 trillion, and continuous development is expected (Business Watch, 2019).

The growth of convenience stores seems to be driven by changes in consumption culture, such as the increase in single-person households, the aging population, and increase in the female working population, small-buying patterns, and the expansion of low-priced consumption. In addition, the long term economic downturn has led to a change in the consumption pattern, which emphasizes convenient accessibility and cost effectiveness (Kim, 2016; Lee, Kim, \& Lee, 2016). In response to these changes in social structure and consumption patterns, convenience stores are steadily expanding their own PB (Private Brand) products, leading to increased sales (Kim, 2016).

PB products mean their own brand and are called 'Private Brand'. In addition, products are expanding not only in their own brands but also in collaboration with products of famous manufacturers. Up to this point, retailer brands have been priced lower than manufacturers' brands but have been perceived to be of poor quality. However, recently PB products, which are introduced as a competitive product, have been selected by consumers because they are cheaper than general products and maintain quality (Choi, 2015). In particular, there are a lot of products that outperform well- 
known manufacturers 'products in PB products. Convenience store PB ramen has risen to the top ranking, overcoming all of the manufacturers' ramen, which has been the first place since the history of convenience stores in the ramen field. They pushed out new foods and created new confectionery categories (Kim, 2016).

Due to the popularity of $\mathrm{PB}$ products, the convenience store industry is competing in developing various $\mathrm{PB}$ products by setting a strategy. The three representative convenience stores, including CU, GS25 and Seven Eleven, are presenting various PB products such as beverages, household goods, and snacks as well as HMR (Home Meal Replacement). As such, the PB sales of the three major convenience stores exceeded $35 \%$ and are recognized as important sales products of convenience stores. As the economic recession continues, the preference for $\mathrm{PB}$ products that focus on price and products is expected to increase steadily, and it is important to strengthen the composition of $\mathrm{PB}$ products to ensure price competitiveness. In addition, despite the economic downturn caused by the economic recession, the dessert market is growing rapidly, reaching 1.5 trillion won in 2015 and 2 trillion won in 2016 (MK News, 2019).

The reason for the growth of dessert market could be explained into corporate and consumer segments. On the corporate side, highly competitive coffee shops and convenience stores focused on marketing for desserts, and distributors brought famous desserts from abroad to increase consumer interest. It is also due to the launch of the brand in various local pastry chef, as well as the expansion of franchise shops specializing in desserts.

On the consumer side, there is a great interest and initiative in the dessert market of young millennium generations in their 20s and 30s who enjoy small luxury, and the expansion of Korean desserts due to lifestyles that pursue healthy body and spirit (Kim, Kim, \& Jeon, 2017). For this reason, convenience store desserts make up a large portion of convenience store $\mathrm{PB}$ products.

As a result, the term 'Pyeon-Di', which means a person who enjoys convenience store desserts, has a large portion of convenience store $\mathrm{PB}$ products. Likewise, the convenience store industry is striving for a lot of development, and the dessert market is also growing. However, previous studies have mainly focused on the selection attributes of convenience store PB products only, studies on convenience store lunch boxes, and studies on dessert cafes (Kim, Kim, \& Jeon, 2017). Although the convenience store dessert market is booming, research on convenience store desserts is insufficient. In the convenience store dessert market, which is rapidly increasing every year, competition for convenience store PB products is also accelerating. As such, it is a good time to study the selection attributes of convenience store desserts. Therefore, this study examines how selection attributes importance of convenience store desserts affect consumer's hedonic value, utilitarian value, and satisfaction as well.

\section{Theoretical Background}

\subsection{Convenience Store Dessert}

Dessert means "to finish the meal, clean up the table" in a dictionary. Desserts are usually in harmony with the foods that came out earlier. In recent years, however, desserts have been considered as independent snacks (MK News, 2019). Originally, dessert was meant for free cake or beverage after the meal. Recently, dessert cafes are increasing as specialty products dealing with cakes, ice cream, pudding, shaved ice, chocolate, macaroons, etc. More and more people like to take time to visit these dessert cafes. Desserts are becoming more and more popular as the main dishes in the restaurant market. The sales volume of the domestic dessert market is steadily growing from 1.5 trillion won in 2015 to 2 trillion won in 2016 (MK News, 2019). As the dessert market grows, convenience store companies have attracted the attention of consumers by offering differentiating products through menus and commercializing desserts into various items.

\subsection{Dessert Selection Attributes for Convenience Store}

The selection attribute is a component necessary to perform the product function required by the consumer, and the criteria change according to the purchase situation, the type of the product, and the consumer. Therefore, a product has a multifaceted and complex characteristic that cannot be evaluated by one standard (Zeithaml, 1988). Kang, Kim, and Lee (2008) also said that the product characteristics that consumers consider important when choosing a product from the various attributes of a brand or products. Such attributes play an important role in the selection and are based on an individual's subjective judgment. It is also an important feature during the purchase decision process when consumers select various attributes.

More broadly, it is the satisfaction of the consumer after making a purchase decision. The selection attribute has a decisive influence on the selection, and thus plays an important role in establishing effective marketing (Oh, 2012). The selection attribute has been steadily studied by many researchers, but the existing studies analyzing the selection attributes of convenience store desserts are insufficient. In this study, in order to empirically analyze the relationship between the selection attributes of convenience store desserts and consumer value, the 
previous researches relating to food and restaurant attributes were reviewed in Table 1 , as follows.

Table 1: Summary of Previous Researches

\begin{tabular}{|c|l|}
\hline $\begin{array}{c}\text { Selection } \\
\text { Attributes }\end{array}$ & \multicolumn{1}{|c|}{ Researchers } \\
\hline Economics & $\begin{array}{l}\text { Lee, Kim, and Lee (2016), Rein, Kotler, and Haider (1993), } \\
\text { Moon and Lyu(2013), Kim(2016) }\end{array}$ \\
\hline Diversity & MK News (2019), Jeong (2014) \\
\hline Convenience & Kim, Kim, and Jeon (2017), Ju (2012), Yoo et al. (2012) \\
\hline Safety & Chung, Yang and Lee (2007), Mohaydin et al. (2017) \\
\hline
\end{tabular}

\subsubsection{Economics of Convenience Store Desserts}

Price is defined as the sum of the monetary costs of a product or service, which is said to be the most influential attribute for consumers because consumers are most concerned about the price when they choose a product (Rein, Kotler, \& Haider, 1993). In addition, because it is specific and measurable, it is considered the most trusted item among consumers' influence on product purchase. Price is the most important factor that consumers consider when purchasing convenience store food. The study by Kim (2016) found that consumers buy PB at a convenience store because of the low price.

\subsubsection{Variety of Convenience Store Desserts}

Consumers seek diversity to reduce the tiredness of repeated consumption behaviors that they would experience in the future. Consumers tend to purchase products of various tastes or brands at the time of purchase, which is called diversity seeking. The pursuit of diversity has a significant impact on perceived values, both hedonic values, utilitarian values and satisfaction (Suk \& Yoon, 2013).

\subsubsection{Convenience of Convenience Dessert}

Convenience is a good property to use, and in the study of HMR selection attributes sold in online malls, convenience is a result of reducing shopping time and cooking process (Yoo, Seo, Choi, \& Lee, 2012). Only convenience among taste, convenience, and quality, which is a selection attribute of convenience store lunches, was found to have a significant positive effect on consumer evaluation. Cha and Lee (2018) found that the convenience of HMR selective attributes had a positive effect on satisfaction (Cha \& Seo, 2019). As discussed above, when people consume convenience store foods, convenience is considered to be important, so this study set convenience as an attribute.

\subsubsection{Safety of Convenience Store Dessert}

Food hygiene and safety is an important part of choosing and eating foods. Chung, Yang, and Lee (2007) found that the most important considerations are the hygienic quality and the freshness of food in HMR selection attribute analysis. Mohaydin, Chand, Aziz, Bashir, and Irfan (2017) study found that food safety has mediating effect on food quality and customer's satisfaction and people are concerned about what they eat is either safe or not and pay attention to what adds up in their food and what they engulf in eating.

Among the PB food selection attribute factors, safety had a significant positive effect on emotional values, and these selection attributes had a impact highly on the perceived value of college students. With reference to the preceding researches, in this study, the selection attributes of convenience store desserts were classified into four selection attributes: economics, diversity, convenience, and safety. Therefore, the following hypotheses are presented.

H1: The economics of desserts would have a significant effect on hedonic value of convenience store customers.

H2: The variety of desserts would have a significant effect on hedonic value of convenience store customers.

H3: The convenience of desserts would have a significant effect on hedonic value of convenience store customers.

H4: The safety of desserts would have a significant effect on hedonic value of convenience store customers.

H5: The economics of desserts would have a significant effect on utilitarian value of convenience store customers.

H6: The variety of desserts would have a significant effect on utilitarian value of convenience store customers.

H7: The convenience of desserts would have a significant effect on utilitarian value of convenience store customers.

H8: The safety of desserts would have a significant effect on utilitarian value of convenience store customers.

\subsection{Perceived Value}

Consumers perceive value by using or purchasing goods or services, affect the emotional response to goods or services (Holbrook \& Corfman, 1985). In other words, after a consumer has a consumption experience with a stimulus or object, the emotional response associated with it may vary depending on how the value is perceived through the experience. Existing researchers divide consumer value into two. It is divided into utilitarian values and hedonic values (Babin, Darden, \& Griffin, 1994). In this study, as a study on the perceptual value of convenience store desserts, this study attempts to find out the value of two kinds of perceptual value factors, hedonic value and utilitarian value. Pleasant consumption is said to represent aspects of consumer behavior that relate to the fantastic, multisensory and emotional aspects of the consumer experience with the product (Holbrook \& Hirschman, 1982). 
In addition, the pleasure value is the emotional benefits such as the fun and enjoyment that consumers experience through shopping. Therefore, when consumers feel positive about a product or service, they are satisfied with the pleasure value (Choi, Ahn, \& Lee, 2015). Accordingly, consumers pursuing pleasure value place importance on the store environment and product composition (Babin, Darden, \& Griffin, 1994).

Pleasant values were also the result of subjective and personal voluntary reactions (Babin, Darden, \& Griffin, 1994). Chandon, Wansink, and Laurent (2000) found that the pleasure values of experience, entertainment, and enjoyment are due to enjoyment and fun rather than the completion of work. Chandon, Wansink, and Laurent (2000) expressed that practical value is a means of purpose, for example, convenience, price reduction, and time saving. In other words, it refers to whether the service provided was beneficial compared to the price paid (Sweeney \& Soutar, 2001). In addition, the practical value can be said to be one of the values to satisfy the practical purpose of the customers visiting the store. In other words, it refers to whether the service provided was beneficial compared to the price paid (Sweeney \& Soutar, 2001). Thus, consumers are satisfied with their practical value when the performance of their product or service exceeds their expectations (Choi, Ahn, \& Lee, 2015). As a result, consumers who seek practical value are more interested in the efficiency than pleasure in purchasing (Lee, 2012).

Seo, Choi, and Lee (2011) found that HMR selection attributes and convenience had a positive relationship with utility values, and found that the selection attributes of convenience store influenced the perceived value of consumers. Customers' hedonic motive has more influence on the importance of empirical attribute and utilitarian motive has more influence on functional attributes than empirical attributes in retail and F\&B industries. (Cha, Oanh, \& Yu, 2018; Cha, \& Park, 2017). As a result of the analysis, it was argued that the optional attributes of convenience foods developed by convenience stores influence the perceived value of consumers. The hypotheses were prepared based on these previous studies.

H9: The hedonic value of desserts would have a significant effect on satisfaction of convenience store customers.

H10: The utilitarian value of desserts would have a significant effect on satisfaction of convenience store customers.

\subsection{Customer Satisfaction}

The satisfaction of consumers who purchase goods in a company can lead to repurchase, and the continuous purchase is directly related to the profit of the company, which is the ultimate purpose of the company. In addition, the concept of customer satisfaction has been perceived as an important content not only in the marketing field but also in the enterprise. Aaker (1997) found that higher level of perceived satisfaction of the customer's desires results in satisfaction. Customer satisfaction is the result of comparing the perceived performance of a product in relation to expectations. Satisfaction is as a result of service performance to satisfy customers' expectations and desires, and pleasure (Hellier, Geursen, Carr, \& Rickard, 2003).

Satisfaction is regarded as an important variable because it directly affects corporate profit growth and leads to consumer repurchase and increased brand trust (Harris \& Goode, 2004). Therefore, it is essential for companies to understand the factors that could increase the satisfaction of convenience store dessert products. According to Zins, Dolnicar, and Mayr (2012), Lu and Chi (2018) found that perceived values influence satisfaction. Figure 1 shows a hypothesis based on the above studies.

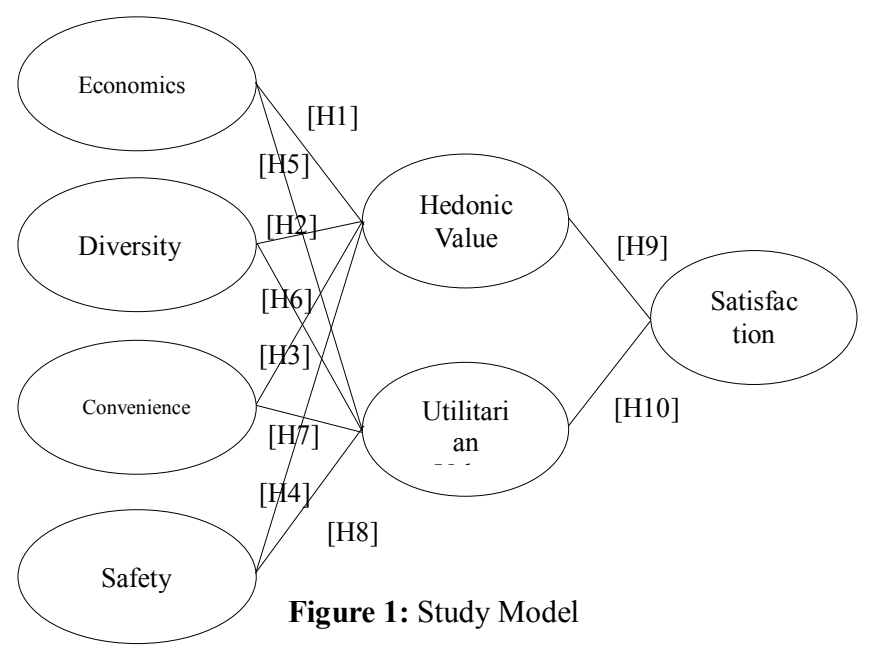

\section{Research Method}

\subsection{Operational Definition of Variables}

Operational definition is the process of expressing the conceptual definition of variables in specific form before measuring it, which refers to the observability presupposed by the actual verification. Based on the results of previous researches, this study was prepared to verify the model and hypothesis. The sub-factors of the convenience store dessert selection attributes are composed of economics, diversity, convenience, and safety. And four economic questions (price, reserve system, events, discounts), four diversity questions (types, new products, various products. marketing channel), convenience 5 questions (close location, purchase procedure, 
packing method, easy storage), safety 4 questions (material, country of origin, nutrition, packaging). The questionnaire consisted of 4 items of hedonic value and 4 items of utilitarian value, and 4 items of satisfaction, total 28 items. Except for demographic questions, questions were asked using a Likert 5 point scale $(1$ point $=$ strongly disagree, 5 points $=$ strongly agree).

\subsection{Sample and Survey Procedures}

A survey was conducted to test the research hypothesis. The questionnaire items for the validation were modified and applied on the basis of previous researches. The survey was conducted through online from April 6, 2019 to April 30, 2019. A total of 303 questionnaires were used for empirical analysis. This study proceeded as follows.

First, exploratory factor analysis and reliability analysis were performed using SPSS 20.0 to verify the validity and reliability of the measured variables. Next, the structural equation model (SEM) was used as a statistical method for hypothesis testing. Then, in order to verify the discriminant and convergent validity between the measured variables, exploratory factor analyzes were performed using Amos 20.0, then the unsuitable factors were removed, and Amos 20.0 was used to confirm the factor analysis. Next, structural equation modelling (SEM) analysis was used as a statistical method to test the hypothesis of this study.

Table 2: Demographic description of samples

\begin{tabular}{|c|c|c|c|}
\hline Variable & Feature & Number & Proportion (\%) \\
\hline \multirow{2}{*}{ Gender } & Male & 95 & $31.4 \%$ \\
\hline & Female & 208 & $68.6 \%$ \\
\hline \multirow{5}{*}{ Age } & Less than 20 & 28 & $9.2 \%$ \\
\hline & $20-29$ & 246 & $81.2 \%$ \\
\hline & $30-39$ & 17 & $5.6 \%$ \\
\hline & $40-49$ & 3 & $1.0 \%$ \\
\hline & Above 50 & 9 & $3.0 \%$ \\
\hline \multirow{4}{*}{$\begin{array}{c}\text { Convenience } \\
\text { Store }\end{array}$} & GS25 & 159 & $52.5 \%$ \\
\hline & $\mathrm{CU}$ & 117 & $38.6 \%$ \\
\hline & Seven Eleven & 16 & $5.3 \%$ \\
\hline & Misc. & 11 & $3.6 \%$ \\
\hline \multirow{4}{*}{ Frequency } & $\begin{array}{c}\text { More than } 2 \sim 3 \text { times per } \\
\text { week }\end{array}$ & 6 & $2.0 \%$ \\
\hline & 1 time per week & 56 & $18.5 \%$ \\
\hline & 1 time per 2 weeks & 91 & $30.0 \%$ \\
\hline & $\begin{array}{l}\text { More than } 2 \text { times in } 2 \\
\text { weeks }\end{array}$ & 150 & $49.5 \%$ \\
\hline
\end{tabular}

Table 2 describes demographic details of the sample. Of the total 303 respondents, 95 were male (31.4\%) and 208 were female (68.6\%). The age distribution was $28(9.2 \%)$ in their teens, $246(81.2 \%)$ in their $20 \mathrm{~s}, 17(5.6 \%)$ in their $30 \mathrm{~s}$, $3(1.0 \%)$ in their $40 \mathrm{~s}$, and $9(3.0 \%)$ was above $50 \mathrm{~s}$. Convenience stores most used by respondents were 159 , GS25 (52.5\%), 117, CU (38.6\%), 16, Seven Eleven (5.3\%), and 11 others $(3.6 \%)$. Frequency of purchase was more than 2-3 times per week $(2.0 \%), 1$ time per week, 56 (18.5\%), 1 time per 2 weeks, $91(30.0 \%)$, more than 2 times in 2 weeks, $150(49.5 \%)$.

\section{Results}

\subsection{Evaluation Metrics}

First of all, reliability and validity analysis were performed on the items measured by multiple items (Churchill, 1979). The Cronbach's coefficients were reviewed after exploratory factor analysis for reliability and validity. As the method of factor extraction, principal component analysis was used, and the factor was extracted based on Eigenvalue 1. The factor rotation method is VARIMAX, and Table 3 and Table 4 show the results of exploratory factor analysis. As shown in Table 3 and Table 4 , all Cronbach's Alpha coefficients are more than 0.6 or close. As a result of exploratory factor analysis, confirmatory factor analysis was performed using Amos 20.0. To test the validity, convergence and discriminant validity were confirmed (Kim, 2010).

Table 3: Exploratory Factor Analysis

\begin{tabular}{|c|c|c|c|c|}
\hline Variables & Safety & Diversity & Convenience & Economics \\
\hline eco02 & .729 & .175 & -.008 & .160 \\
\hline eco03 & .749 & -.011 & .183 & .209 \\
\hline $\operatorname{div01}$ & .009 & .779 & .220 & .256 \\
\hline $\operatorname{div} 02$ & .328 & .673 & .183 & .147 \\
\hline $\operatorname{div03}$ & .120 & .775 & .145 & .251 \\
\hline $\operatorname{div} 04$ & .141 & .597 & .101 & .281 \\
\hline con03 & .100 & .134 & .753 & .221 \\
\hline con04 & .148 & .161 & .748 & .143 \\
\hline saf01 & .097 & .221 & .277 & .759 \\
\hline saf02 & .279 & .259 & .075 & .825 \\
\hline saf03 & .200 & .230 & .171 & .800 \\
\hline saf04 & .146 & .209 & .332 & .722 \\
\hline $\begin{array}{c}\text { Variance (\%) Total } \\
\text { Variance: 62.3\% }\end{array}$ & 17.1 & 16.4 & 16.0 & 12.6 \\
\hline Cronbach's Alpha & 0.592 & 0.790 & 0.658 & 0.882 \\
\hline
\end{tabular}

Note: eco $=$ Economics, div $=$ Diversity, con $=$ Convenience, saf $=$ Safety 
Table 4: Exploratory Factor Analysis

\begin{tabular}{|c|c|c|c|}
\hline Variables & $\begin{array}{c}\text { Utilitarian } \\
\text { value }\end{array}$ & Satisfaction & Hedonic value \\
\hline satis01 & .864 & .206 & .293 \\
\hline satis02 & .790 & .251 & .426 \\
\hline satis03 & .834 & .263 & .354 \\
\hline uti01 & .188 & .886 & .092 \\
\hline uti02 & .225 & .862 & .139 \\
\hline hed01 & .395 & .128 & .667 \\
\hline hed02 & .283 & .108 & .859 \\
\hline hed03 & .260 & .109 & .851 \\
\hline Variance (\%) & 30.7 & 29.1 & 21.7 \\
\hline Total Variance: $81.6 \%$ & 0.780 & 0.826 & 0.929 \\
\hline Cronbach's Alpha &
\end{tabular}

Note: satis $=$ satisfaction, $u$ ti $=$ utilitarian value, hed $=$ hedonic value

As shown in Table 5, the chi-squared value for the measurement model is significant $(\mathrm{p}<0.001)$, but the NFI (normed fit index) and RFI (relative fit index) are sensitive to sample size and model complexity. It was judged to evaluate the model fit by taking into account the fit index, incremental fit index (IFI), and comparative fit index (CFI) (Bearden, Sharma, \& Teel, 1982). Overall model fit was assessed satisfactory with NFI $=0.895, \mathrm{RFI}=0.866, \mathrm{IFI}=$ $0.933, \mathrm{TLI}=0.914$ and $\mathrm{CFI}=0.932$. AVE (average variance extracted) and composite reliability meet the criteria suggested by Bagozzi and Yi (1988) (AVE 0.5 or higher, composite reliability 0.6 or higher), and the standardized path coefficients are statistically significant $(\mathrm{p}<0.001)$. Convergent validity was confirmed. Table 5 shows the confirmatory factor analysis results.

In order to verify the discriminant validity between the factors, average variance extraction (AVE) verification was performed. This is a method of comparing the squared correlation value between the AVE value and the factors. At this time, discrimination validity is proved when the AVE value is larger than the correlation square value.

Table 5: Confirmatory factor analysis

\begin{tabular}{|c|c|c|c|c|}
\hline Variables & Measure & $\begin{array}{l}\text { Standardized } \\
\text { Regression } \\
\text { coefficient }\end{array}$ & CR & AVE \\
\hline \multirow{2}{*}{ economics } & eco02 & 0.640 & \multirow{2}{*}{0.598} & \multirow{2}{*}{0.427} \\
\hline & eco03 & 0.666 & & \\
\hline \multirow{4}{*}{ diversity } & $\operatorname{div} 01$ & 0.776 & \multirow{4}{*}{0.598} & \multirow{4}{*}{0.514} \\
\hline & $\operatorname{div} 02$ & 0.776 & & \\
\hline & $\operatorname{div} 03$ & 0.776 & & \\
\hline & $\operatorname{div} 04$ & 0.589 & & \\
\hline \multirow{2}{*}{ convenience } & con 01 & 0.734 & \multirow{2}{*}{0.671} & \multirow{2}{*}{0.505} \\
\hline & con02 & 0.687 & & \\
\hline \multirow{4}{*}{ safety } & saf01 & 0.759 & \multirow{4}{*}{0.887} & \multirow{4}{*}{0.505} \\
\hline & saf02 & 0.876 & & \\
\hline & saf03 & 0.850 & & \\
\hline & saf04 & 0.767 & & \\
\hline \multirow{2}{*}{$\begin{array}{l}\text { utilitarian } \\
\text { value }\end{array}$} & uti03 & 0.762 & \multirow{2}{*}{0.781} & \multirow{2}{*}{0.641} \\
\hline & uti04 & 0.838 & & \\
\hline \multirow{3}{*}{ hedonic value } & hed02 & 0.696 & \multirow{3}{*}{0.836} & \multirow{3}{*}{0.641} \\
\hline & hed03 & 0.851 & & \\
\hline & hed04 & 0.827 & & \\
\hline \multirow{3}{*}{ satisfaction } & satis02 & 0.872 & \multirow{3}{*}{0.930} & \multirow{3}{*}{0.815} \\
\hline & satis03 & 0.916 & & \\
\hline & satis04 & 0.920 & & \\
\hline
\end{tabular}

$\mathrm{X}^{2}=384.169(\mathrm{df}=149, \mathrm{p}=0.000), \mathrm{NFI}=0.895, \mathrm{RFI}=0.866, \mathrm{IFI}=0.933, \mathrm{TLI}=0.914$, $\mathrm{CFI}=0.932, \mathrm{RMSEA}=0.072(p<0.001)$

As a result, as shown in Table 6, the value of AVE is larger than 0.5 , and all of them are larger than the nondiagonal correlation squares in related columns and rows. Therefore, the discriminant validity that a suitable difference should be shown in the measurement result between components is verified.

Table 6: Discrimination validity through correlation analysis

\begin{tabular}{|c|c|c|c|c|c|c|c|}
\hline & Convenience & Economics & Diversity & Safety & Hedonic Value & Utilitarian Value & Satisfactory \\
\hline Convenience & 0.711 & & & & & \\
\hline Economics & 0.493 & 0.653 & & & & & \\
\hline Diversity & 0.595 & 0.521 & 0.717 & & & \\
\hline Safety & 0.576 & 0.567 & 0.661 & 0.815 & & \\
\hline Hedonic Value & 0.481 & 0.466 & 0.567 & 0.666 & 0.794 & & \\
\hline Utilitarian Value & 0.643 & 0.469 & 0.569 & 0.551 & 0.392 & 0.801 & 0.585 \\
\hline Satisfactory & 0.591 & 0.508 & 0.601 & 0.678 & 0.777 & 0.903 \\
\hline
\end{tabular}

Note: The values shown on the diagonal are the square root of AVE, and the rest are correlation coefficients. 


\subsection{Research Hypothesis Test}

To test the hypothesis, Amos 20.0 was used. The fit index was satisfactory with the chi-squared value 384.169 (df = $149, \mathrm{p}<0.001)$, NFI $=0.895, \mathrm{RFI}=0.866$, IFI $=0.933$, TLI $=0.914$, CFI $=0.932$, and RMSEA $=0.072$ for the study model. Table 7 shows the hypothesis test results for the main effects from hypothesis 1 to hypothesis 10 .

Table 7: Results of research hypothesis

\begin{tabular}{|c|c|c|c|c|}
\hline Hypothesis & Paths & Path Coefficient & $t$ - value & Results \\
\hline H1 & $\begin{array}{c}\text { economy } \rightarrow \\
\text { hedonic }\end{array}$ & 0.101 & 0.865 & Reject \\
\hline $\mathrm{H} 2$ & $\begin{array}{l}\text { diversity } \longrightarrow \\
\text { hedonic }\end{array}$ & 0.288 & $2.052 *$ & Accept \\
\hline $\mathrm{H} 3$ & $\begin{array}{c}\text { convenience } \rightarrow \\
\text { hedonic }\end{array}$ & 0.098 & 0.703 & Reject \\
\hline $\mathrm{H} 4$ & safety $\rightarrow$ hedonic & 0.736 & $5.384 * * *$ & Accept \\
\hline H5 & $\begin{array}{c}\text { economy } \rightarrow \\
\text { utilitarian }\end{array}$ & 0.051 & 0.869 & Reject \\
\hline H6 & $\begin{array}{c}\text { diversity } \rightarrow \\
\text { utilitarian }\end{array}$ & 0.136 & 1.910 & Reject \\
\hline $\mathrm{H} 7$ & $\begin{array}{c}\text { convenience } \rightarrow \\
\text { utilitarian }\end{array}$ & 0.300 & $3.872 * * *$ & Accept \\
\hline H8 & $\begin{array}{l}\text { safety } \rightarrow \\
\text { utilitarian }\end{array}$ & 0.102 & 1.549 & Reject \\
\hline H9 & $\begin{array}{l}\text { hedonic value } \rightarrow \\
\text { satisfaction }\end{array}$ & 0.586 & $11.014 * * *$ & Accept \\
\hline $\mathrm{H} 10$ & $\begin{array}{l}\text { utilitarian value } \\
\rightarrow \text { satisfaction }\end{array}$ & 0.667 & $6.114 * * *$ & Accept \\
\hline
\end{tabular}

The hypothesis test on the main effects showed that diversity and safety had a positive effect on the pleasure value, and the effect of economics and convenience on the pleasure value was not significant. This suggests that the variety and safety of convenience store dessert selection attributes can be a major factor in the consumer's pleasure value. On the other hand, the economics and convenience of convenience store desserts did not have a significant effect on the pleasure value. In addition, convenience had a positive effect on the practical value, and economics, diversity, and safety had no significant effect on the practical value. This indicates that convenience among the convenience store dessert selection attributes can be a major factor in the practical value of consumers. On the other hand, the path coefficient connecting pleasure and practical value to satisfaction was found to be significant, indicating a positive effect on the satisfaction of consumers who perceived the perceptional value of convenience store desserts. The results of verification are shown in Figure 2.

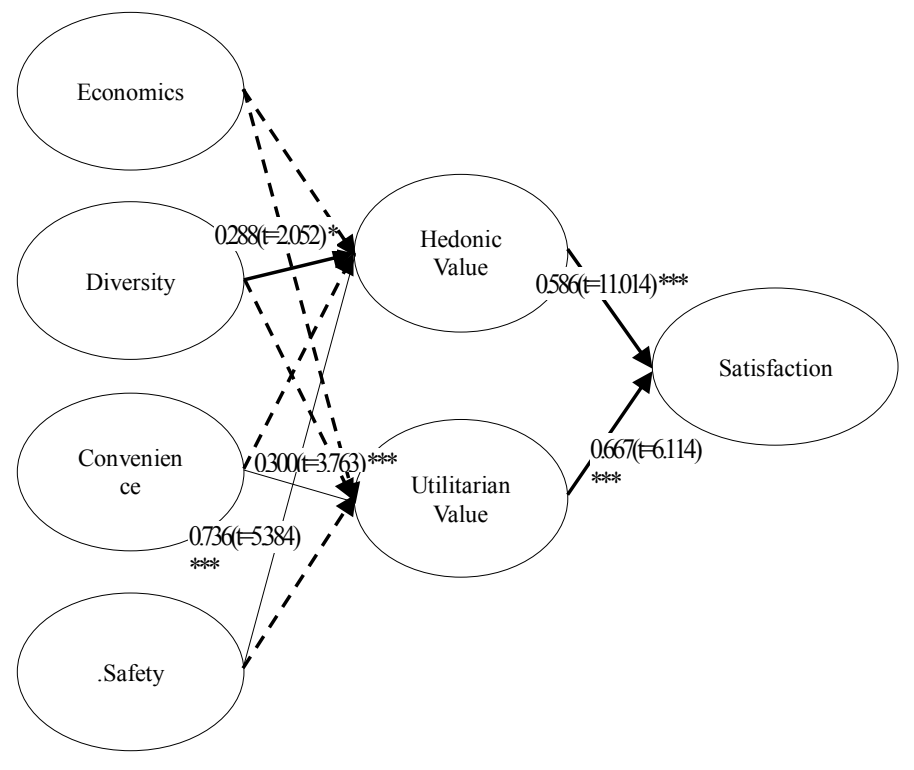

Figure 2: Results of research hypothesis

\section{Conclusions}

The purpose of this study is to find out which of the selection attributes of convenience store desserts have more important influence on consumers' perceived value and satisfaction. Based on the previous researches, we examined the effect of four optional elements on the perceived value that were considered to be more suitable to the selection attributes of convenience store desserts and causal relationship was reviewed. The results of this analysis will provide meaningful implications for retailers selling convenience store desserts and companies participating in R\&D with the desserts.

The conclusions according to the results of this study are as follows. First, diversity and safety among the selection attribute factors of convenience store desserts have a statistically significant effect on the hedonic value, and economics and convenience have no effect. It revealed that the results of magnitude influence on hedonic value are safety $(\beta=0.736, \mathrm{t}$-value 5.384, $\mathrm{p}<0.001)$, and diversity $(\beta$ $=0.288, \mathrm{t}$-value 2.052, $\mathrm{p}<0.05)$. Second, convenience has a statistically significant effect on the practical value, however, economics, diversity, and safety have no statistically significant differences. The Factors influencing practical value were convenience $(\beta=0.300, \mathrm{t}$-value 3.872 , $\mathrm{p}<0.001)$, diversity $(\beta=0.136)$, safety $(\beta=0.102)$, and economics $(\beta=0.051)$. Finally, the statistical results showed that the path coefficients of the utilitarian value and the hedonic value of convenience store desserts were satisfied. 
Comparing the magnitude of influence, the practical value $(\beta=0.667, \mathrm{t}$-value $6.114, \mathrm{p}<0.001)$ had a greater impact than the pleasure value $(\beta=0.586, \mathrm{t}$-value $11.014, \mathrm{p}<$ $0.001)$ on satisfaction. The suggestions through the above conclusions are as follows.

\section{Implications}

First, among the selection attributes of convenience store desserts, diversity and stability have a positive effect on the pleasure value. Based on this, companies should develop event-based marketing such as the display and promotion of various foods, discount events and SNS, which arouse customers' curiosity. In addition, it is important to keep the products safe and hygienic, and to display clean images using decent ingredients. On the other hand, economics and convenience of convenience store dessert selection attributes do not affect the value of pleasure. It can be seen that customers are pursuing pleasure consumption that emphasizes pleasure and interest rather than price and convenience when selecting a product.

Second, convenience among the selection attributes of convenience store desserts had a positive effect on the practical value. It is necessary to reinforce desserts with simple packaging design, easy to stock containers, excellent quality for price, and develop more various products in the future.

Third, consumers using convenience store desserts had a similar positive influence on satisfaction with both the pleasure and practical value, so that the perceived value could be continuously satisfied without biasing either side.

\section{Limitations}

This study has some limitations and suggests future research directions as follows. First, economics, diversity, convenience, and safety were considered as the selection attributes in research model. Further research is needed to add palatability, quality, reliability, health, and package design etc. Second, the total number of samples is only 303, and there are limitation for generalization because there are a lot of samples in their 20s. If future research is classified into various fields such as various demographic characteristics, distributors, and product lines, it will be possible to understand the products more clearly.

\section{Reference}

Aaker, J. L. (1997). Dimensions of brand personality. Journal of Marketing Research, 34(3), 347-356.
Babin, B. J., Darden, W. R., \& Griffin, M. (1994). Work and/or fun: measuring hedonic and utilitarian shopping value. Journal of Consumer Research, 20(4), 644-656.

Bagozzi, R. P., \& Yi, Y. (1988). On the evaluation of structural equation models. Journal of the Academy of Marketing Science, 16(1), 74-94.

Bearden, W. O., Sharma, S., \& Teel, J. E. (1982). Sample size effects on chi square and other statistics used in evaluating causal models. Journal of Marketing Research, 19(4), 425-430.

Business Watch (2019). Now 'convenience store era', Convenience store beats both department stores and large marts. Retrieved November 10, 2019, from

http://news.bizwatch.co.kr/article/consumer/2019/08/14/0028.

Cha, S. S., \& Lee, S. H. (2018). The effects of HMR selection attributes on repurchase intention by shopping channel. Journal of Distribution Science, 16(3), 13-21.

Cha, S. S., \& Park, C. (2017). Consumption value effects on shopping mall attributes: Moderating role of on/off-line channel type. Journal of Distribution Science, 15(6), 5-12.

Cha, S. S., \& Seo, B. K. (2019). The effect of brand trust of home meal replacement on repurchasing in online shopping. Journal of Business, Economics, and Environmental Studies, 9(3), 2126.

Cha, S. S., Oanh, V. T. K., \& Yu, W. J. (2018). The Effect of Eating-Out Motives on Restaurant Attributes at Shopping Mall. Journal of Distribution Science, 16(1), 37-46.

Chandon, P., Wansink, B., \& Laurent, G. (2000). A benefit congruency framework of sales promotion effectiveness. Journal of Marketing, 64(4), 65-81.

Choi, S. I., Ahn, J. S., \& Lee, S. B. (2015). The effects of the selective attributes of coffee shop on perceived value and customer loyalty. Journal of Tourism and Leisure Research, 27(7), 319-340.

Choi, Y. M. (2015). A Study on the Impact of Attraction and Compromise Effects on Choice Probability of Private Brands. Journal of the Korea Academia-Industrial Cooperation Society, 16(3), 1806-1814.

Chung, L. N., Yang, I. S., \& Lee, H. Y. (2007). Preference, satisfaction, and repurchase intention of consumers for home meal replacements (HMR) by product categories. Korean Journal of Food and Cookery Science, 23(3), 388-400.

Churchill Jr, G. A. (1979). A paradigm for developing better measures of marketing constructs. Journal of Marketing Research, 16(1), 64-73.

Harris, L. C., \& Goode, M. M. (2004). The four levels of loyalty and the pivotal role of trust: a study of online service dynamics. Journal of Retailing, 80(2), 139-158.

Hellier, P. K., Geursen, G. M., Carr, R. A., \& Rickard, J. A. (2003). Customer repurchase intention: A general structural equation model. European Journal of Marketing, 37(11/12), 1762-1800.

Holbrook, M. B., \& Corfman, K. P. (1985). Quality and value in the consumption experience: Phaedrus rides again. Perceived Quality, 31(2), 31-57.

Holbrook, M. B., \& Hirschman, E. C. (1982). The experiential aspects of consumption: Consumer fantasies, feelings, and fun. Journal of Consumer Research, 9(2), 132-140.

Jeong, J. S. (2014). Research on Effects of Components of the Package Design for CVS PB (Convenience store Private Brand) Products upon Consumer Attitudes and Purchase 
Intention. A Journal of Brand Design Association of Korea, 12(4), 100-109.

Ju, S. Y. (2012). Study on importance-performance analysis regarding selective attributes of home meal replacement (HMR). Journal of the Korean Society of Food Science and Nutrition, 41(11), 1639-1644.

Kang, C. H., Kim, N. H., \& Lee, G. H. (2008). Positioning map analysis for imported wine brands by nationality in Korean market. Journal of Tourism Studies, 10(4), 67-78.

Kim, J. H., Kim, Y. S., \& Jeon, Y. J. (2017). The effects of the convenience store lunch-box selection attributes on satisfaction and behavioral intentions. The Korea Academic Society of Tourism \& Leisure, 28(1), 353-370.

Kim, M. J. (2016). Influence of Consumption Patterns and Satisfaction for Convenience Store Private Brand Foods. Journal of the Korea Academia-Industrial Cooperation Society, 17(3), 629-637.

Kim, S. H. (2010). Effects of perceived attributes on the purchase intention of smart-phone. The Journal of the Korea Contents Association, 10(9), 318-326.

Lee, B. H. (2012). Structural relationship among utilitarian. hedonic shopping value, emotional responses, store attitude and loyalty of sporting goods consumer. The Korea Journal of Sports Science, 21(6), 915-930.

Lee, E. Y., Kim, M. M., \& Lee, S. B. (2016). The effects of the CVS private brand menu product attributes on satisfaction, intention to repurchase and brand trust. International Journal of Tourism and Hospitality Research, 30(3), 173-184.

Lu, L., \& Chi, C. G. Q. (2018). An examination of the perceived value of organic dining. International Journal of Contemporary Hospitality Management, 30(8), 2826-2844. https://doi.org/10.1108/IJCHM-05-2017-0267

MK News (2019). Convenience store dessert market, 'star products' led to overall sales. Retrieved November 10, 2019, from https://www.mk.co.kr/news/society/view/2019/04/240680/

Mohaydin, G., Chand, A., Aziz, B., Bashir, M., \& Irfan, J. (2017). Effect of food quality on customer perceived satisfaction level and mediating effect of food safety on them. International Journal of New Technology and Research, 3(1). 34-41

Moon, G. Y., \& Lyu, H. C. (2013). A Study on the Spatial Presentation Strategies for Cafe as The Third Space-Focused on the cafes located in regions where Street culture was formed. Korean Institute of Interior Design Journal, 22(5), 6877.

Oh, M. J. (2012). An Examination of the Role of Hotel Choice Attribute between Personal Value and Satisfaction: Focusing on Moderating and Mediating Effect. Korea Journal of Tourism and Hospitality Research, 26(1), 403-419.

Rein, I., Kotler, P., \& Haider, D. (1993). Marketing Places: Attracting Investment, Industry, and Tourism to Cities, States, and Nations. New York, NY: The Free Press.

Seo, K. H., Choi, W. S., \& Lee, S. B. (2011). A study on the influence of the selective attributes of home meal replacement on perceived utilitarian value and repurchase intention: Focus on consumers of large discount and department stores. Journal of the East Asian Society of Dietary Life, 21(6), 934-947.

Suk, K., \& Yoon, S. O. (2013). The Effect of Consumption Quantity on Variety Seeking: Analysis of Instant Noodle Purchase at Household level. Journal of Channel and Retailing, 18(4), 24-29.

Sweeney, J. C., \& Soutar, G. N. (2001). Consumer perceived value: The development of a multiple item scale. Journal of Retailing, 77(2), 203-220.

Yoo, Y. H., Seo, K. H., Choi, W. S., \& Lee, S. B. (2012). The effect of consideration attribute of HMR featured in home shopping online malls on perceived value and repurchasing intention. Journal of Foodservice Management, 15, 197-218.

Zeithaml, V. A. (1988). Consumer perceptions of price, quality, and value: a means-end model and synthesis of evidence. Journal of Marketing, 52(3), 2-22.

Zins, A. H., Dolnicar, S., \& Mayr, T. (2012). Extensions on the conceptualization of customer perceived value: insights from the airline industry. International Journal of Culture, Tourism and Hospitality Research, 6(4), 356-376. 